\title{
A specialized airway management team for COVID-19 patients: a retrospective study of the experience of two Canadian hospitals in Toronto
}

\section{Une équipe spécialisée dans la prise en charge des voies aériennes pour les patients atteints de la COVID-19 : une étude rétrospective de l'expérience de deux hôpitaux canadiens à Toronto}

\author{
Nicola Jarvis, MBBS • Simone Schiavo, MD · Justyna Bartoszko, MD • Martin Ma, MD • \\ Ki Jinn Chin, MD $\cdot$ Matteo Parotto, MD
}

Received: 11 August 2021/Revised: 26 October 2021/Accepted: 27 October 2021/Published online: 8 December 2021

(C) Canadian Anesthesiologists' Society 2021

\begin{abstract}
Background In the COVID-19 pandemic, an unprecedented number of individuals required endotracheal intubation. To safely face these challenges, expert intubation teams were formed in some institutions. Here, we report on the experience of emergency rapid intubation teams (ERITs) in two Canadian hospitals.
\end{abstract}

\footnotetext{
N. Jarvis, MBBS · J. Bartoszko, MD · M. Ma, MD

Department of Anesthesiology and Pain Medicine, University of Toronto, EN 429 - 200 Elizabeth Street, Toronto, ON M5G 2C4, Canada
}

\begin{abstract}
Department of Anesthesia and Pain Management, Toronto General Hospital, Toronto, ON, Canada

\section{S. Schiavo, MD · K. J. Chin, MD}

Department of Anesthesiology and Pain Medicine, University of Toronto, EN 429 - 200 Elizabeth Street, Toronto, ON M5G 2C4, Canada
\end{abstract}

\footnotetext{
Department of Anesthesia and Pain Management, Toronto Western Hospital, Toronto, ON, Canada

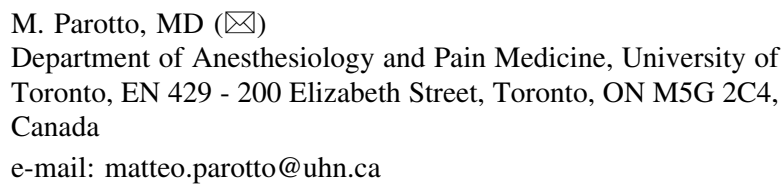

Methods We retrospectively collected data on all airway management procedures in confirmed or suspected COVID-19 patients performed by ERITs at two academic hospitals between 3 April and 17 June 2020. The coprimary outcomes were incidence of periprocedural adverse events (hypoxemia, hypotension, and cardiac arrest within $15 \mathrm{~min}$ of intubation) and first-attempt intubation success rate. Secondary outcomes included number of intubation attempts, device used to achieve successful airway management, and adherence to personal protective equipment (PPE) protocols.

Results During the study period, 123 patients were assessed for airway management, with 117 patients receiving airway interventions performed by the ERIT. The first-attempt success rate for intubation was $92 \%$, and a videolaryngoscope was the final successful device in 93\% of procedures. Hypoxemia (peripheral oxygen saturation $\left.\left[\mathrm{SpO}_{2}\right]<90 \%\right)$ occurred in 28 patients $(24 \%)$ and severe hypoxemia $\left(\mathrm{SpO}_{2}<70 \%\right)$ occurred in ten patients $(9 \%)$. Hypotension (systolic blood pressure $[\mathrm{SBP}]<90 \mathrm{~mm} \mathrm{Hg}$ ) occurred in 37 patients (32\%) and severe hypotension (SBP $<65 \mathrm{~mm} \mathrm{Hg}$ ) in 11 patients (9\%). Adherence to recommended PPE use among providers was high.

Conclusion In this cohort of critically ill patients with respiratory failure requiring time-sensitive airway management, specialized ERIT teams showed high rates of successful airway management with high adherence to PPE use. Hypoxemia and hemodynamic instability were common and should be anticipated within the first $15 \mathrm{~min}$ following intubation.

Study registration www.ClinicalTrials.gov (NCT04689724); registered 30 December 2020. 


\section{Résumé}

Contexte Pendant la pandémie de COVID-19, un nombre sans précédent de patients ont dî bénéficier d'une intubation endotrachéale. Pour faire face en toute sécurité à ces défis, des équipes d'experts en intubation ont étéformées dans certains établissements. Nous rendons compte ici de l'expérience d'équipes d'intubation rapide d'urgence (ou ERIT, pour Emergency Rapid Intubation Team) dans deux hôpitaux canadiens.

Méthode Nous avons colligé rétrospectivement les données concernant toutes les interventions de prise en charge des voies aériennes chez les patients COVID-19 confirmés ou suspectés réalisées par les ERIT dans deux hôpitaux universitaires entre le 3 avril et le 17 juin 2020. Les deux critères d'évaluation principaux étaient l'incidence d'événements indésirables péri-procédure (hypoxémie, hypotension et arrêt cardiaque dans les 15 minutes suivant l'intubation) et le taux de réussite de l'intubation à la première tentative. Les critères d'évaluation secondaires comprenaient le nombre de tentatives d'intubation, le dispositif utilisé pour parvenir au succès de la prise en charge des voies aériennes et le respect des protocoles concernant les équipements de protection individuelle (EPI).

Résultats Au cours de la période à l'étude, 123 patients ont été évalués pour une prise en charge des voies aériennes, et 117 patients ont bénéficié d'interventions au niveau des voies aériennes réalisées par l'ERIT. Le taux de réussite de la première tentative d'intubation était de $92 \%$, et un vidéolaryngoscope a été le dispositif menant à une intubation réussie dans $93 \%$ des interventions. Des épisodes d'hypoxémie (saturation périphérique en oxygène $\left.\left[\mathrm{SpO}_{2}\right]<90 \%\right)$ sont survenus chez 28 patients (24\%) et dix patients $(9 \%)$ ont souffert d'hypoxémie sévère $\left(\mathrm{SpO}_{2}<\right.$ $70 \%$ ). Des épisodes d'hypotension (tension artérielle systolique [TAS] $<90 \mathrm{mmHg}$ ) sont survenus chez 37 patients (32\%) et 11 patients (9\%) ont souffert d'hypotension sévère $(T A S<65 \mathrm{mmHg}$ ). Le respect de l'utilisation recommandée des EPI chez les soignants était élevé.

Conclusion Dans cette cohorte de patients gravement malades atteints d'insuffisance respiratoire et nécessitant une prise en charge des voies aériennes urgente, les équipes spécialisées de l'ERIT ont montré des taux élevés de succès de prise en charge des voies aériennes, avec une adhésion élevée aux protocoles d'utilisation des EPI. L'hypoxémie et l'instabilité hémodynamique étaient fréquentes et devaient être anticipées dans les 15 premières minutes suivant l'intubation.

Enregistrement de l'étude $w w w$.ClinicalTrials.gov (NCTO 4689724); enregistrée le 30 décembre 2020.
Keywords airway management $\cdot$ COVID-19

As a result of the COVID-19 pandemic, unprecedented numbers of patients required advanced support for respiratory failure worldwide. ${ }^{1-3}$ Endotracheal intubation in COVID-19 patients is a highly specialized procedure ${ }^{4}$ that carries risk both to patients and attending healthcare workers (HCWs). Healthcare workers involved in airway management for patients infected with coronaviruses may be at high risk of infection due to aerosol and droplet exposure during the procedure. During the severe acute respiratory syndrome coronavirus-1 (SARS-CoV-1) outbreak, HCWs performing endotracheal intubation had a relative risk [RR] of 13 for developing SARS compared with others caring for these patients. ${ }^{5,6}$ Initial data from the COVID-19 pandemic (caused by SARS-CoV-2) suggests that $10 \%$ of HCWs developed an infection, although causality with professional exposure as opposed to social exposure could not be established with certainty. ${ }^{7}$ Expert recommendations were released to guide safe endotracheal intubation in these settings, and included directions on team composition and dynamics, use of videolaryngoscopy, and rapid sequence induction (RSI) with administration of hypnotics and neuromuscular blocking agents (NMBAs). ${ }^{8,9}$ Given the underlying physiologic compromise in critically ill patients, the process is associated with a significant risk of lifethreatening severe adverse events (SAEs), such as hypoxemia, hypotension, and cardiac arrest. ${ }^{3,10-12}$ To optimize resources and reduce the risk to patients and HCWs, expert airway teams were developed in several centres in Canada and in other countries to perform endotracheal intubations in COVID-19 patients. The structure of these airway teams differed across countries and healthcare systems. A group from the UK recently published the experience of a London hospital, ${ }^{13}$ showing that a highly-skilled designated intubation team utilizing a protocolized, early tracheal intubation model may improve patient and staff safety.

To the best of our knowledge, the Canadian experience with similar specialized teams has not been reported to date. In this retrospective study, we describe patient outcomes at two academic hospitals in Toronto where airway management teams were developed and responsible for urgent airway management in all patients with suspected or known COVID-19. Our hypothesis was that the establishment of designated airway teams would be associated with a high rate of successful first-attempt intubation and maintain patient and provider safety. 


\section{Methods}

At the onset of the pandemic, a dedicated rapid response team for airway management of all COVID-19 suspected or confirmed patients (internally named the "Emergency rapid intubation team" [ERIT]) was developed at both Toronto General and Toronto Western Hospital, and its activities were designed to follow a shared protocolized approach. Prior to the institution of this team, airway management in the emergency rooms (ERs) and intensive care units (ICUs) was provided by ER and ICU physicians, with anesthesiologists available as back-up in case of an unanticipated or anticipated difficult airway. On medical and surgical wards, airway management was typically provided either by ICU physicians or, in case of code blue scenarios, by an anesthesiologist or supervised anesthesia trainee (resident or fellow). Videolaryngoscopy was not the routine first-line device prior to ERIT, and RSI was not the standard in all cases, with the choice of device and medications at the discretion of individual providers.

The ERIT was active $24 \mathrm{hr}$ a day and seven days a week. The ERIT team was composed of one attending anesthesiologist, two operating room registered nurses (OR RNs), one anesthesia assistant (AA), and one patient attendant, with each team working a 12-hr shift. Prepacked boxes containing the required equipment were developed and stored in a designated location. Dedicated pagers and overhead public address system activation codes were utilized to request ERIT assistance, and the team responded to requests from anywhere in the hospital, including ICUs and ERs.

Didactic teaching and simulation sessions were attended by team members before the "go-live" date. The team would meet at the beginning of each shift to review algorithms and simulate clinical scenarios, including donning and doffing of personal protective equipment (PPE), which was in accordance with the recommendations from the World Health Organization (WHO). ${ }^{14}$ The roles of each team member were preidentified and designated as follows: airway manager (anesthesiologist), assistance with airway equipment and airway management (AA), assistance with medications, monitoring, hemodynamics (OR RN1), "runner" and safety officer for PPE donning and doffing (OR RN2), and assistance with provision of additional equipment and transportation (attendant). Procedures were documented on standardized clinical forms.

The protocol included hemodynamic optimization, preoxygenation, use of RSI (for NMBAs, either succinylcholine at $1.5 \mathrm{mg} \cdot \mathrm{kg}^{-1}$ or rocuronium at 1.2 $\mathrm{mg} \cdot \mathrm{kg}^{-1}$ were recommended; the choice of hypnotics was left to the discretion of the attending anesthesiologist and included one or more of the following agents: ketamine, propofol, midazolam, and fentanyl) and videolaryngoscopy as a first-line device (Storz C-MAC ${ }^{\circledR}$ airway management cart with reusable blades, KARL STORZ SE \& Co. KG, Tuttlingen, Germany). The blade size and type (Macintoshblade or D-blade) used for the initial attempt was chosen by the individual anesthesiologist. We did not routinely use apneic oxygenation during intubation with low-flow or high-flow nasal oxygen. Following recommendations from experts published at the onset of the pandemic, our strategy included intubation early in the course of illness for patients with respiratory failure, as judged by the attending physician. Typically, intubation was performed in patients with any of the following: persistent or worsening tachypnea (RR $>25$ ) or a trajectory of increasing respiratory distress despite medical management, marginal and/or rapidly deteriorating oxygen saturations despite supplemental oxygenation, and bilateral infiltrates on chest imaging. ${ }^{15}$ The clinical evaluation of potential risk factors for difficult airway and hemodynamic instability was performed at the discretion of the attending anesthesiologist.

We retrospectively collected data on all airway management procedures performed by the ERIT. The clinical registry was used to identify patients who received care by this team, and a retrospective chart review was conducted collecting data on demographics, specifics of airway management (e.g., technique, location, number of attempts) and related SAEs (hypoxemia, hypotension, and cardiac arrest within 15 min of intubation) in confirmed or suspected COVID-19 patients at participating centres. Anonymized data were entered in a centralized, encrypted and password-protected database. The study was approved by the University Health Network Research Ethics Board (REB 20-5620, 2 August 2020). This study conforms with the Strengthening the Reporting of Observational Studies in Epidemiology (STROBE) guidelines $^{16}$ and was preregistered prior to commencement in January 2021 of data extraction and analysis under ClinicalTrials.gov Identifier NCT04689724 (registration date, 30 December 2020).

Data were examined for missing and incomplete data. Results are presented as means (standard deviation) for continuous variables or absolute values with percentages (\%) for count data. Contingency table data were compared using the Chi square test for cell count values equal to or greater than 5, and Fisher's exact test for cell counts less than 5. An exploratory analysis examining the association of preoperative patient characteristics and induction medication dosing with outcomes was conducted. The co-primary outcomes of interest were hypotension (defined as a systolic blood pressure (SBP) $<90 \mathrm{~mm} \mathrm{Hg}$ within 15 min of induction) and hypoxemia (defined as a postinduction oxygen saturation $<90 \%$ within $15 \mathrm{~min}$ of 
induction). Relative risk ratios were calculated for individual predictors using log-binomial regression, given the incidence of our outcomes of interest was $>10 \% .^{17}$ Induction medication dosing, preinduction hypoxemia, and preinduction hypotension were examined as predictors of interest in separate models, each adjusted for the baseline patient characteristics of age, sex, and overall condition (awake, drowsy, or cardiopulmonary arrest), which were $a$ priori specified given our limited number of outcome events. $^{18}$

\section{Results}

From 3 April to 17 June 2020, 123 COVID-19 patients (suspected or confirmed) with respiratory failure were assessed by the specialized airway teams at the two hospitals, with 117 (95\%) ultimately requiring airway management. Table 1 summarizes the details. Incomplete data were noted in five (4\%) procedures.

A total of 43 anesthesiologists were involved as the primary airway managers in at least one intubation during the study period. The majority of airway management procedures $(n=70 / 117 ; 60 \%)$ were performed in the ICU. A total of $29(25 \%)$ were performed in the ER, and 20 $(17 \%)$ in medical/surgical wards (either high acuity step down unit beds [level 2], or regular ward beds) (Table 2). One instance of airway management $(1 \%)$ was conducted in the OR.

\section{Procedure}

Rapid sequence induction (predetermined induction doses, high-dose neuromuscular blockade, no bag-mask ventilation, with or without cricoid pressure) or modified RSI (predetermined induction medication doses with some element of titration depending on patient response, no bagmask ventilation) was employed in all cases. A videolaryngoscope was the final successful device used for airway management in most cases requiring endotracheal intubation $(109 / 117 ; 93 \%)$, with a high firstattempt success rate $(108 / 117 ; 92 \%)$ (Table 2$)$. In seven cases $(6 \%)$, there was a pre-existing endotracheal airway and an exchange was required. Out of the nine intubations with more than one documented attempt, 7/9 (78\%) achieved success with videolaryngoscopy (Table 3). More than two attempts at intubation were required in $2 / 117$ ( $2 \%$ ) cases; one intubation required three attempts and another required four attempts (Table 3). A flexible reusable bronchoscope was required in 2/117 (2\%) cases, and a tracheostomy (tube exchange) was involved in one case $(1 \%)$ (Table 4).
Table 1 Characteristics of patients assessed by the emergency response intubation team

Patient characteristics prior to assessment for intubation $N=123$

Demographics

Age (yr), mean (SD)

$60(16)$

Sex, $n /$ total $N(\%)$

Female

BMI $\left(\mathrm{kg} \cdot \mathrm{m}^{-2}\right)$, mean (SD)

Condition and vital signs at assessment

COVID-19 status at time of assessment,

$n /$ total $N(\%)$

PCR-confirmed SARS-CoV2 infection ${ }^{\mathrm{a}}$

$31 / 123$

Suspected positive for SARS-CoV2 ${ }^{\mathrm{a}}$

PCR assay negative

Baseline systolic blood pressure (mm Hg), mean (SD)

Baseline diastolic blood pressure $(\mathrm{mm} \mathrm{Hg})$, mean (SD)

70 (17)

Baseline heart rate $\left(\mathrm{min}^{-1}\right)$, mean (SD)

$106(27)$

Baseline oxygen saturation by pulse oximetry (\%), mean 93 (9) (SD)

Baseline oxygen saturation by pulse oximetry, $n /$ total $N(\%)$

$\geq 90 \%$

$83 / 123$

$81-90 \%$

$15 / 123$

$71-80 \%$

$6 / 123(5 \%)$

$\leq 70 \%$

$19 / 123$

$(15 \%)$

Mental status, $n /$ total $N(\%)$

Awake

$32 / 123$

Drowsy

$56 / 123$

Unconscious

Cardiopulmonary arrest

Resuscitation and oxygen therapies at time of assessment

Bag-mask ventilation being provided at time of team arrival, $n /$ total $N(\%)$

Chest compressions being provided at time of team arrival, $n /$ total $N(\%)$

Baseline oxygen flow rate $\left(\mathrm{L} \cdot \mathrm{min}^{-1}\right)$, mean (SD)

Baseline inspired fraction of oxygen, mean (SD)

Oxygen delivery device type, $n /$ total $N(\%)$

Non-invasive ventilation

$4 / 123(3 \%)$

$2 / 123(2 \%)$

Face mask

Nasal prongs

High-flow nasal cannula
/123 $(1 \%)$

$19 / 123$

$14 / 123$

(11.4)

$12(8)$

$0.85(0.29)$

$8 / 123(7 \%)$ 
Table 1 continued

Patient characteristics prior to assessment for intubation $N=123$

\begin{tabular}{lc}
\hline Other & $15 / 123$ \\
& $(12 \%)$ \\
Not specified & $66 / 123$ \\
& $(54 \%)$ \\
\hline
\end{tabular}

${ }^{a}$ Allplex ${ }^{\text {TM }} 2019$ n-CoV assay (Seegene Inc., Seoul, South Korea) $\mathrm{BMI}=$ body mass index; $\mathrm{PCR}=$ polymerase chain reaction

Serious adverse events

\section{Hypoxemia}

Within $15 \mathrm{~min}$ of airway management, hypoxemia (peripheral oxygen saturation $\left[\mathrm{SpO}_{2}\right]<90 \%$ ) occurred in 28 patients $(24 \%)$, with severe hypoxemia $\left(\mathrm{SpO}_{2}<70 \%\right)$ present in ten patients $(9 \%)$. Patients with preinduction hypoxemia had a higher RR of postintubation hypoxemia in unadjusted (RR, 2.39; 95\% confidence interval [CI], 1.26 to $4.54 ; P \leq 0.01$ ) and adjusted models (aRR, $2.17 ; 95 \%$ CI, 1.08 to $4.35 ; P=0.03)$. There were only $9(8 \%)$ situations where multiple attempts were required for airway management. With multiple intubation attempts, the incidence of positive pressure ventilation prior to intubation was more common $(2 / 9 ; 22 \%)$ compared with single intubation attempts $(11 / 108 ; 10 \%)$, although the difference was not statistically significant (Fisher's exact test, $P=0.28$ ). The single incidence of supraglottic airway use occurred in an individual who had hypoxemia prior to induction of anesthesia and required multiple intubation attempts; hypoxemia was resolved after successful intubation.

\section{Hypotension}

Hypotension within 15 min of airway management $(\mathrm{SBP}<$ $90 \mathrm{~mm} \mathrm{Hg}$ ) occurred in 37/117 patients (32\%), and severe hypotension (SBP $<65 \mathrm{~mm} \mathrm{Hg}$ ) in 11/117 patients (9\%) (Table 3). Patients with pre-existing hypotension prior to intubation were more likely to have hypotension after intubation in unadjusted models (RR, 1.79; 95\% CI, 1.05 to 3.06; $P=0.03$ ], but not after adjustment for age, sex, and preinduction clinical condition (aRR, 1.55; 95\% CI, 0.93 to $2.60 ; P=0.09)$. A total of $51 / 117(44 \%)$ patients received phenylephrine boluses at the time of induction, with a mean (SD) dose of 362 (39) $\mu \mathrm{g}$ and a dose range of $80-2,200 \mu \mathrm{g}$. A total of $12 / 117$ patients $(10 \%)$ received ephedrine with a mean (SD) dose of 17 (11) $\mathrm{mg}$, and a range of $10-50 \mathrm{mg}$, and $8 / 117$ patients $(7 \%)$ required
Table 2 Intubation location characteristics and induction strategy

Characteristics of intubation location and induction $\quad N=117$ strategy

\section{Intubation setting}

Location of intubation, $n /$ total $N(\%)$

Operating room

$1 / 117(1 \%)$

Emergency department

$29 / 117$

Intensive care unit (level 3)

$70 / 117$

$(60 \%)$

High acuity monitored bed (level 2)

$13 / 117$

Ward

$7 / 117(6 \%)$

Negative pressure room, $n /$ total $N(\%)$

$41 / 117$

$(35 \%)$

Airway management strategies

Preoxygenation device, n/total N (\%)

None

$1 / 117(1 \%)$

Nasal prongs

$3 / 117(3 \%)$

Face mask (Hudson, non-rebreather)

$6 / 117(5 \%)$

Tavish mask

$67 / 117$

Bag valve mask

High-flow nasal cannula

$6 / 117(5 \%)$

Pre-existing endotracheal airway

$7 / 117(6 \%)$

Other

$2 / 117(2 \%)$

Positive pressure ventilation applied prior to endotracheal intubation, $n /$ total $N(\%)$

$13 / 117$

Intubating aids utilized, n/total N (\%)

Stylet

$92 / 117$

Bougie

$5 / 117(4 \%)$

Airway exchange catheter

$3 / 117(3 \%)$

Temporizing supraglottic airway use, $n /$ total $N(\%)$

$1 / 117(1 \%)$

Number of attempts required for definitive airway insertion $\mathrm{n} /$ total $\mathrm{N}(\%)$

1

$108 / 117$

2

$7 / 117(6 \%)$

$1 / 117(1 \%)$

$1 / 117(1 \%)$

Final successful technique used for airway management, n/total N (\%)

Videolaryngoscopy - Storz C-MAC $\AA^{\text {a }}$

$108 / 117$

Videolaryngoscopy - McGRATH ${ }^{\mathrm{TM}} \mathrm{MAC}^{\mathrm{b}}$

$1 / 117(1 \%)$

Fibreoptic bronchoscope

$2 / 117(2 \%)$

Direct laryngoscopy

$0 / 117(0 \%)$

Tracheostomy

$1 / 117(1 \%)$

Definitive airway charted, n/total N (\%)

Endotracheal tube

$111 / 117$

(95\%) 
Table 2 continued

\begin{tabular}{lc}
\hline $\begin{array}{l}\text { Characteristics of intubation location and induction } \\
\text { strategy }\end{array}$ & $N=117$ \\
\hline Tracheostomy (pre-existing) & $1 / 117(1 \%)$ \\
Initial confirmation method for endotracheal placement & \\
of airway, n/total N (\%) & $103 / 117$ \\
Capnometry or capnography & $(88 \%)$ \\
& $3 / 117(3 \%)$ \\
Auscultation & $4 / 117(3 \%)$ \\
\hline
\end{tabular}

a KARL STORZ SE \& Co. KG, Tuttlingen, Germany

b Medtronic/Covidien LLC, Mansfield, MA, USA

Table 3 Outcomes of patients within 15 min of airway management

\begin{tabular}{ll}
\hline Parameter & $\begin{array}{l}\text { Proportion, } n / \text { total } \\
N(\%)\end{array}$ \\
\hline $\begin{array}{l}\text { Lowest oxygen saturation by pulse oximetry } \\
\text { within } 15 \text { min of intubation }\end{array}$ \\
$>90 \%$ & $79 / 117(68 \%)$ \\
$81-90 \%$ & $13 / 117(11 \%)$ \\
$70-80 \%$ & $5 / 117(4 \%)$ \\
$<70 \%$ & $10 / 117(9 \%)$ \\
Lowest systolic blood pressure within 15 min of & \\
intubation (mm Hg) & \\
$>90$ & $72 / 117(62 \%)$ \\
$75-90$ & $17 / 117(15 \%)$ \\
$65-75$ & $9 / 117(8 \%)$ \\
$<65$ & $11 / 117(9 \%)$ \\
Heart rate at 15 min after intubation & \\
$\quad($ beats·min & \\
$<40$ & \\
$40-120$ & $4 / 117(3 \%)$ \\
$120-140$ & $80 / / 117(68 \%)$ \\
$>140$ & $16 / 117(14 \%)$ \\
\hline
\end{tabular}

epinephrine boluses, with a mean (SD) dose of 269 (324) $\mu \mathrm{g}$, and a dose range of $20-1,000 \mu \mathrm{g}$. Centrally infused vasopressors at the time of induction were used in 15/117 (13\%) patients, with a dose range for norepinephrine of $0.03-0.3 \mu \mathrm{g} \cdot \mathrm{kg}^{-1} \cdot \mathrm{min}^{-1}$, a dose range for vasopressin of 2-6 units. $\mathrm{hr}^{-1}$, and a dose range for epinephrine of 0.2-0.3 $\mu \mathrm{g} \cdot \mathrm{kg}^{-1} \cdot \mathrm{min}^{-1}$ (Table 5). The type of hypnotic used for induction was not associated with postinduction hypotension in either unadjusted or adjusted models. Neither was the total medication dose used for the agents fentanyl, midazolam, or propofol; however, there was a statistically significant association between the total ketamine dose used and hypotension in both unadjusted and adjusted models (Table 6).

\section{Cardiac arrests}

No new cardiac arrests were reported after induction and intubation (Table 4). At the time of ERIT team arrival, three $(3 \%)$ patients were actively receiving chest compressions, and one patient (1\%) was documented as being periarrest, although it was unclear if chest compressions had been initiated prior to ERIT activation, and were not required after team arrival.

\section{Protective personal equipment (PPE)}

Gloves, N95 masks, face shields, or goggles and caps were used in $100 \%$ of cases by the professional conducting the intubation. A gown was used in $98 \%$ of cases, and $100 \%$ of procedures were supervised by a designated "spotter" (Table 7).

\section{Discussion}

We report the results of a retrospective study on the airway management of patients with suspected or confirmed COVID-19 requiring airway management at two academic hospitals during the first wave of the pandemic in Canada.

In this cohort managed by a designated expert team, we observed widespread use of videolaryngoscopy as a firstline device, high first-attempt success rates, and very high adherence to recommended PPE practices. These data appear overall in line with reports from other COVID-19 airway management teams. ${ }^{13}$ While accurate comparisons are not possible and some differences in the definitions exist, a previous, large epidemiological study in critically ill patients that included management by a variety of healthcare teams ${ }^{12}$ reported peri-intubation rates of cardiovascular instability of $42 \%$, hypoxia $\left(\mathrm{SpO}_{2}<80 \%\right)$ of $9 \%$, and difficult intubation (intubation requiring more than two attempts) of 5\%. Such findings reinforce the impact of pre-existing physiologic compromise on airway management in the critically ill. ${ }^{19}$ Important planning considerations include patient tolerance of the apneic interval that precedes intubation and ventilation, and the potential of medications used for anesthesia induction to contribute to hemodynamic instability. ${ }^{19}$ The choice of induction agent was not generally observed to have a significant association with hypotension in this study; however, a weak association was observed between increasing ketamine dose and postinduction hypotension. This may be related to the known myocardial depressant 
Table 4 Details of intubations requiring more than one attempt

\begin{tabular}{|c|c|c|c|}
\hline $\begin{array}{l}\text { Patient COVID-19 status at } \\
\text { the time of airway } \\
\text { management }\end{array}$ & $\begin{array}{l}\text { Number } \\
\text { of } \\
\text { attempts }\end{array}$ & $\begin{array}{l}\text { Manual bag-mask } \\
\text { ventilation required between } \\
\text { attempts }\end{array}$ & Event details \\
\hline Confirmed PCR-positive & 2 & Unknown & $\begin{array}{l}\text { Details of initial unsuccessful technique not described. Final } \\
\text { successful technique was with STORZ C-MAC }{ }^{\text {a }}{ }^{a}\end{array}$ \\
\hline Suspected positive & 2 & No & $\begin{array}{l}\text { Initially no view with McGRATH }{ }^{\mathrm{TM}} \mathrm{MAC}^{\mathrm{b}} \text { videolaryngoscope. }^{\text {Successful intubation with STORZ C-MAC }{ }^{\mathrm{a}}{ }^{\mathrm{a}}}\end{array}$ \\
\hline Confirmed PCR-negative & 2 & Yes & $\begin{array}{l}\text { Initially unable to intubate with direct laryngoscopy. Successful } \\
\text { intubation with STORZ C-MAC }{ }^{\text {a }}\end{array}$ \\
\hline Confirmed PCR-positive & 2 & No & $\begin{array}{l}\text { Oropharyngeal bleeding requiring two attempts to successfully } \\
\text { intubate. First unsuccessful attempt not described. Successful } \\
\text { intubation completed using a STORZ C-MAC®. }{ }^{\text {a }}\end{array}$ \\
\hline Suspected positive & 2 & No & $\begin{array}{l}\text { First look done awake with lidocaine topicalization. Second } \\
\text { successful attempt after first look done with paralysis and a STORZ } \\
\text { C-MAC } .^{\text {a }}\end{array}$ \\
\hline Suspected positive & 2 & No & No details provided. There was no use of a supraglottic airway. \\
\hline Confirmed PCR-positive & 2 & Yes & $\begin{array}{l}\text { The stylet within the endotracheal tube was not angulated sufficiently } \\
\text { for anterior vocal cord location. The patient was successfully } \\
\text { intubated using a STORZ C-MAC }{ }^{\mathrm{a}}{ }^{\mathrm{a}}\end{array}$ \\
\hline Confirmed PCR-positive & 3 & $\begin{array}{l}\text { No, however supraglottic } \\
\text { airway inserted }\end{array}$ & $\begin{array}{l}\text { Encrusted blood obstructed the view to the airway, and the vocal } \\
\text { cords were not visualized. An i-gel }{ }^{\mathrm{c}} \text { supraglottic airway was } \\
\text { inserted after the first attempt. For the second attempt, a new } \\
\text { laryngoscope blade was used, and a bougie was added, but this was } \\
\text { unsuccessful alone. For the third attempt, a fibreoptic bronchoscope } \\
\text { was used to successfully intubate the trachea. }\end{array}$ \\
\hline Confirmed PCR-positive & 4 & Yes & $\begin{array}{l}\text { A good view of the vocal cords was seen each time; however, it was } \\
\text { difficult to pass a } 7.5 \text { endotracheal tube. A STORZ C-MAC }{ }^{\text {a }}{ }^{\text {was }} \text { was } \\
\text { used for eventual successful intubation. }\end{array}$ \\
\hline
\end{tabular}

a KARL STORZ SE \& Co. KG, Tuttlingen, Germany

b Medtronic/Covidien LLC, Mansfield, MA, USA

c Intersurgical Ltd, Wokingham, Berks., UK

$\mathrm{PCR}=$ polymerase chain reaction

Table 5 Induction medication details

\begin{tabular}{llll}
\hline Induction medication & Proportion of patients receiving, $n /$ total $N(\%)$ & Mean (SD) dose used & Range of doses used \\
\hline Hypnotics & $25 / 117(21 \%)$ & $150(90) \mu \mathrm{g}$ & $50-500 \mu \mathrm{g}$ \\
Fentanyl & $53 / 117(45 \%)$ & $2.7(1.4) \mathrm{mg}$ & $0.5-5 \mathrm{mg}$ \\
Midazolam & $64 / 117(55 \%)$ & $65(26) \mathrm{mg}$ & $20-100 \mathrm{mg}$ \\
Ketamine & $36 / 117(31 \%)$ & $59(35) \mathrm{mg}$ & $10-200 \mathrm{mg}$ \\
Propofol & $101 / 117(86 \%)$ & $87(26) \mathrm{mg}$ & $10 \mathrm{mg}$ to $150 \mathrm{mg}$ \\
Neuromuscular blocking agents & $213(72) \mathrm{mg}$ & $80 \mathrm{mg}$ to $320 \mathrm{mg}$ \\
Rocuronium & $29 / 117(25 \%)$ & $362(39) \mu \mathrm{g}$ & $80-2,200 \mu \mathrm{g}$ \\
Succinylcholine & $51 / 117(44 \%)$ & $17(11) \mathrm{mg}$ & $10-50 \mathrm{mg}$ \\
Requirement for vasopressor boluses & $269(324) \mu \mathrm{g}$ & $20-1,000 \mu \mathrm{g}$ \\
Phenylephrine & $12 / 117(10 \%)$ & & \\
Ephedrine & $8 / 117(7 \%)$ & & \\
Epinephrine & &
\end{tabular}


Table 6 Association of induction medication doses with postinduction hypotension

\begin{tabular}{|c|c|c|c|c|}
\hline \multirow[t]{2}{*}{ Induction agent } & \multicolumn{2}{|l|}{ Unadjusted log-binomial regression } & \multicolumn{2}{|l|}{ Adjusted log-binomial regression } \\
\hline & Relative risk ( $95 \%$ confidence interval) & $P$ value & Relative risk ( $95 \%$ confidence interval) & $P$ value \\
\hline Fentanyl dose (per 50- $\mu \mathrm{g}$ increment) & $1.06(0.87$ to 1.31$)$ & 0.55 & $1.06(0.87$ to 1.31$)$ & 0.56 \\
\hline Midazolam dose (per 1-mg increment) & $0.92(0.76$ to 1.12$)$ & 0.41 & $0.97(0.83$ to 1.15$)$ & 0.75 \\
\hline Ketamine dose (per 10-mg increment) & $1.07(1.00$ to 1.15$)$ & 0.04 & $1.08(1.01$ to 1.16$)$ & 0.03 \\
\hline Propofol dose (per 10-mg increment) & $0.96(0.86$ to 1.07$)$ & 0.46 & $0.95(0.87$ to 1.05$)$ & 0.34 \\
\hline
\end{tabular}

Models were adjusted for patient age, sex, and overall condition (awake, drowsy, cardiopulmonary arrest). Postinduction hypotension was defined as a systolic blood pressure $<90 \mathrm{~mm} \mathrm{Hg}$ within $15 \mathrm{~min}$ of induction.

Table 7 Personal protective equipment and practices among team members

\begin{tabular}{ll}
\hline Equipment & Proportion utilized by intubator, $n /$ total $N(\%)$ \\
\hline N95 mask & $114 / 114(100 \%)$ \\
Face shield & $113 / 114(99 \%)$ \\
Goggles & $61 / 114(54 \%)$ \\
Gown & $112 / 114(98 \%)$ \\
Cap & $114 / 114(100 \%)$ \\
Gloves (single or double gloving) & $114 / 114(100 \%)$ \\
Shoe covers & $9 / 114(8 \%)$ \\
Use of a designated "spotter" for PPE breaches & $114 / 114(100 \%)$ \\
\hline
\end{tabular}

$\mathrm{PPE}=$ personal protective equipment

effects of ketamine, or may be due to residual confounding related to ketamine being chosen as an induction agent in sicker patients. ${ }^{20,21}$ Patient harm can be minimized by anticipating and preparing to manage these adverse effects, as well as having skilled and experienced team members working as a cohesive unit. ${ }^{22}$ This is borne out by the absence of periprocedural cardiac arrest in our population, which was associated with prompt administration of supplemental vasopressors in appropriate doses.

When we instituted the ERIT system at our centres, we decided to involve only experienced airway management providers to minimize risks to team members and patients. Hence, only consultant anesthesiologists were the designated airway manager on ERIT. For similar reasons, it was decided that the first-line device would be a videolaryngoscope, and that RSI would be employed in all cases. These factors may have contributed to the high firstattempt and overall success rates observed. Indeed, in the INTUBE study, having anesthesia as primary specialty (odds ratio, $0.53 ; 95 \% \mathrm{CI}, 0.41$ to 0.69 ), and the use of a videolaryngoscope (odds ratio, $0.60 ; 95 \% \mathrm{CI}, 0.42$ to 0.85 ) were significantly associated with a reduced likelihood of first-pass intubation failure. ${ }^{12} \mathrm{We}$ observed a nearcomplete adherence to PPE protocols, with higher rates compared with other experiences described in the literature. In an international observational study of more than 4,000 emergent tracheal intubations in COVID-19 patients, Wong et al. reported that PPE in compliance with WHO standards was utilized in $87.5 \%$ of cases, ${ }^{23}$ compared with over $98 \%$ in our centres. Canadian data from the IntubateCOVID database showed that WHO standards were not met in $3.7 \%$ of procedures. ${ }^{24}$ The repeated simulation training and the presence of a "spotter" who ensured proper PPE practice among team members may have played an important role in these figures. ${ }^{25-27}$ Nevertheless, even with these considerations in mind, there were (albeit very rare) breaches in best practices (such as not wearing a gown), and providers should always be mindful of the importance of adequate PPE.

The study has several inherent limitations that merit discussion. First, those related to the retrospective design and limited sample size of the study. Second, we present the experience of two academic centres, part of the same institution, which adopted a similar approach. The findings may not necessarily be generalizable to other settings. Third, the periprocedural data were extracted from a standardized clinical form that was filled in by one of the 
ERIT team members immediately following the event, rather than by an independent observer; hence, there is a potential for reporting and observer bias. Additionally, we did not capture data regarding the clinical evaluation by the attending anesthesiologist of potential risk factors for difficult intubation.

We also have no direct comparison data from intubations in the critically ill population at our institution conducted by non-specialized airway teams, limiting our capability to ascertain the impact of the airway team per se on patient outcomes or HCW safety. No data are available on the incidence of COVID-19 infection in ERIT HCWs. We had initially planned, with REB approval, to interview team members to assess whether they had developed signs, symptoms, or confirmed infection related to ERIT activities; however, the response rate to a call for voluntary participation in this interview was too low to provide meaningful information.

\section{Conclusion}

We present data from a Canadian experience with a consultant anesthesiologist-led specialized team for airway management in patients with COVID-19 experiencing respiratory failure. A highly protocolized team-based approach was used, and only experienced providers performed airway management. In this setting, we observed high adherence to PPE recommendations, high first-attempt success rates at intubation, and periprocedural rates of severe hypotension and hypoxemia of $9 \%$ each. We believe that this model of emergency airway management in critically ill patients could be readily implemented in other Canadian settings, and may be beneficial for provider and patient safety during future pandemics or in subsequent waves of the present COVID-19 pandemic.

\begin{abstract}
Author contributions Matteo Parotto and Ki Jinn Chin contributed to the study conception and design and manuscript preparation. Nicola Jarvis, Simone Schiavo, and Martin Ma contributed to the data collection. Justyna Bartoszko contributed to the statistical analysis. All authors contributed to the manuscript amendment.
\end{abstract}

Acknowledgements The authors would like to express their gratitude to all members of the Emergency Rapid Intubation Team, who selflessly stepped-up to help amid the uncertainties and fears in the first wave of the COVID-19 pandemic, and the collaboration from all members of the Critical Care and Emergency departments and all clinical units at our hospitals. We are indebted to Mrs. Samareh Ajami, research coordinator, for her invaluable help in the organization of this study.

Disclosures None.

Funding statement Matteo Parotto and Ki Jinn Chin are recipients of a Research Commendation Award from the Department of
Anesthesiology and Pain Medicine, University of Toronto, and Toronto General and Western Hospitals. J. Bartoszko is the recipient of a Merit Award from the Department of Anesthesiology and Pain Medicine, University of Toronto, and Toronto General Hospital.

Editorial responsibility This submission was handled by Dr. Stephan K.W. Schwarz, Editor-in-Chief, Canadian Journal of Anesthesia/Journal canadien d'anesthésie.

\section{References}

1. Wu Z, McGoogan JM. Characteristics of and important lessons from the coronavirus disease 2019 (COVID-19) outbreak in China: summary of a report of 72314 cases from the Chinese Center for Disease Control and Prevention. JAMA 2020; 323: 1239-42.

2. Grasselli G, Pesenti A, Cecconi M. Critical care utilization for the COVID-19 outbreak in Lombardy, Italy: early experience and forecast during an emergency response. JAMA 2020; 323: 1545-6.

3. Richardson S, Hirsch JS, Narasimhan $M$, et al. Presenting characteristics, comorbidities, and outcomes among 5700 patients hospitalized with COVID-19 in the New York City area. JAMA 2020; 323: 2052-9.

4. Meng L, Qiu H, Wan L, et al. Intubation and ventilation amid the COVID-19 outbreak: Wuhan's experience. Anesthesiology 2020; 132: $1317-32$.

5. Tran K, Cimon K, Severn M, Pessoa-Silva CL, Conly J. Aerosol generating procedures and risk of transmission of acute respiratory infections to healthcare workers: a systematic review. PLoS One 2012; DOI: https://doi.org/10.1371/journal. pone.0035797.

6. Caputo KM, Byrick R, Chapman MG, Orser BJ, Orser BA. Intubation of SARS patients: infection and perspectives of healthcare workers. Can J Anesth 2006; 53: 122-9.

7. El-Boghdadly K, Wong DJ, Owen R, et al. Risks to healthcare workers following tracheal intubation of patients with COVID19: a prospective international multicentre cohort study. Anaesthesia 2020; 75: 1437-47.

8. Brewster DJ, Chrimes N, Do TB, et al. Consensus statement: Safe Airway Society principles of airway management and tracheal intubation specific to the COVID-19 adult patient group. Med J Aust 2020; 212: 472-81.

9. Cook TM, El-Boghdadly K, McGuire B, McNarry AF, Patel A, Higgs $A$. Consensus guidelines for managing the airway in patients with COVID-19: guidelines from the Difficult Airway Society, the Association of Anaesthetists the Intensive Care Society, the Faculty of Intensive Care Medicine and the Royal College of Anaesthetists. Anaesthesia 2020; 75: 785-99.

10. Jabre $P$, Avenel A, Combes $X$, et al. Morbidity related to emergency endotracheal intubation-a substudy of the KETAmine SEDation trial. Resuscitation 2011; 82: 517-22.

11. Mosier JM, Joshi R, Hypes C, Pacheco G, Valenzuela T, Sakles $J C$. The physiologically difficult airway. West J Emerg Med 2015; 16: 1109-17.

12. Russotto V, Myatra SN, Laffey JG, et al. Intubation practices and adverse peri-intubation events in critically ill patients from 29 countries. JAMA 2021; 325: 1164-72.

13. Ahmad I, Jeyarajah J, Nair G, et al. A prospective, observational, cohort study of airway management of patients with COVID-19 by specialist tracheal intubation teams. Can J Anesth 2021; 68: 196-203. 
14. World Health Organization. Rational use of personal protective equipment for coronavirus disease (COVID-19) and considerations during severe shortages: interim guidance, 6 April 2020. Available from URL: https://apps.who.int/iris/ handle/10665/331695 (accessed October 2021)

15. Brown CA 3rd, Mosier JM, Carlson JN, Gibbs MA. Pragmatic recommendations for intubating critically ill patients with suspected COVID-19. J Am Coll Emerg Physicians Open 2020; 1: 80-4.

16. von Elm E, Altman DG, Egger M, Pocock SJ, Gøtzsche PC, Vandenbroucke JP; STROBE Initiative. The Strengthening the Reporting of Observational Studies in Epidemiology (STROBE) statement: guidelines for reporting observational studies. Ann Intern Med 2007; 147: 573-7.

17. Prasad K, Jaeschke R, Wyer P, Keitz S, Guyatt G; EvidenceBased Medicine Teaching Tips Working Group. Tips for teachers of evidence-based medicine: understanding odds ratios and their relationship to risk ratios. J Gen Intern Med 2008; 23: 635-40.

18. Vittinghoff $E, M c C$ ulloch $C E$. Relaxing the rule of ten events per variable in logistic and cox regression. Am J Epidemiol 2007; 165: 710-8.

19. Lapinsky SE. Endotracheal intubation in the ICU. Crit Care 2015; DOI: https://doi.org/10.1186/s13054-015-0964-z.

20. Ishimaru T, Goto T, Takahashi J, et al. Association of ketamine use with lower risks of post-intubation hypotension in hemodynamically-unstable patients in the emergency department. Sci Rep 2019; DOI: https://doi.org/10.1038/s41598019-53360-6.

21. April MD, Arana A, Schauer SG, et al.; NEAR Investigators. Ketamine versus etomidate and peri-intubation hypotension: a
National Emergency Airway Registry study. Acad Emerg Med 2020; 27: 1106-15.

22. Mosier JM, Sakles JC, Law JA, Brown CA 3rd, Brindley PG. Tracheal intubation in the critically ill. Where we came from and where we should go. Am J Respir Crit Care Med 2020; 201: 775-88.

23. Wong DJ, El-Boghdadly K, Owen $R$, et al. Emergency airway management in patients with COVID-19: a prospective international multicenter cohort study. Anesthesiology 2021; DOI: https://doi.org/10.1097/ALN.0000000000003791.

24. Parotto M, Cavallin F, Bryson GL, Chin KJ; intubateCOVID Canadian collaborators; intubateCOVID International Coordinating Centre. Risks to healthcare workers following tracheal intubation of patients with known or suspected COVID19 in Canada: data from the intubateCOVID registry. Can J Anesth 2021; 68: 425-7.

25. Loh PS, Chaw SH, Shariffuddin II, Ng CC, Yim CC, Hashim NH. A developing nation's experience in using simulation-based training as a preparation tool for the coronavirus disease 2019 outbreak. Anesth Analg 2021; 132: 15-24.

26. Pan $D$, Rajwani $K$. Implementation of simulation training during the COVID-19 pandemic: a New York hospital experience. Simul Healthc 2021; 16: 46-51.

27. Andonian J, Kazi S, Therkorn J, et al. Effect of an intervention package and teamwork training to prevent healthcare personnel self-contamination during personal protective equipment doffing. Clin Infect Dis 2019; 69(Suppl 3): S248-55.

Publisher's Note Springer Nature remains neutral with regard to jurisdictional claims in published maps and institutional affiliations. 